\section{Moving Evolution Education Forward: A Systematic Analysis of Literature to Identify Gaps in Collective Knowledge for Teaching}

\author{
M. A. Ziadie and T. C. Andrews* \\ Department of Genetics, University of Georgia, Athens, GA 30602
}

\begin{abstract}
Evolution is a unifying theory in biology and is challenging for undergraduates to learn. An instructor's ability to help students learn is influenced by pedagogical content knowledge (РCK), which is topic-specific knowledge of teaching and learning. Instructors need PCK for every topic they teach, which is a tremendous body of knowledge to develop alone. However, investigations of undergraduate thinking and learning have produced collective PCK that is available in peer-reviewed literature. Currently, it is unclear whether the collective PCK available adequately addresses the topics in evolution that college instructors teach. We systematically examined existing literature to determine what collective PCK for teaching evolution is available and what is missing. We conducted an exhaustive literature search and analyzed 316 relevant papers to determine: the evolutionary topics addressed; whether the focus was student thinking, assessment, instructional strategies, or goals; and the type of work (e.g., empirical, literature review). We compared the collective PCK available in the literature with the topics taught in a sample of 32 undergraduate evolution courses around the country. On the basis of our findings, we propose priorities for the evolution education research community and propose that $\mathrm{PCK}$ is a useful lens for guiding future research on teaching and learning biology.
\end{abstract}

\section{INTRODUCTION}

Evolution is a unifying and explanatory theory for all of biology and is therefore a core concept in undergraduate biology education (American Association for the Advancement of Science [AAAS], 2011). However, it is also challenging to learn (e.g., Nehm and Reilly, 2007; Andrews et al., 2011; Price and Perez, 2016). Students often possess intuitive conceptions about the world that do not align with a scientifically accurate understanding of evolution (Nehm et al., 2010; Smith, 2010; Coley and Tanner, 2012). Additionally, understanding evolution requires knowledge of abstract concepts that are hard for people of all ages, such as randomness in mutation and genetic drift (e.g., Lecoutre et al., 2006; Garvin-Doxas and Klymkowsky, 2008). Student difficulties translate into challenges faced by instructors. Undergraduates retain inaccurate ideas about evolutionary concepts even after carefully planned lessons (e.g., Phillips et al., 2012; Price et al., 2014). One factor that influences the effectiveness of instruction is teacher knowledge (e.g., Hill et al., 2005; Sadler et al., 2013). Helping students learn evolution likely requires more than just content knowledge.

One type of teacher knowledge associated with student learning is pedagogical content knowledge (PCK; e.g., Hill et al. 2005; Sadler et al., 2013). PCK is knowledge of teaching and learning used in the everyday work of instructors (Shulman, 1987). PCK is topic specific, meaning that an instructor needs distinct PCK for each topic taught (e.g., natural selection, speciation; Gess-Newsome, 2015). This knowledge goes beyond disciplinary knowledge scientists use in their day-to-day research (Ball et al., 2008). For example, an evolutionary biologist thinks carefully about whether
Kathryn E. Perez, Monitoring Editor Submitted August 31, 2017; Revised November 13, 2017; Accepted November 22, 2017

CBE Life Sci Educ March 1, 2018 17:ar11 DOI:10.1187/cbe.17-08-0190

*Address correspondence to: T. C. Andrews (tandrews@uga.edu).

(c) 2018 M. A. Ziadie and T. C. Andrews. CBE-Life Sciences Education (๑) 2018 The American Society for Cell Biology. This article is distributed by The American Society for Cell Biology under license from the author(s). It is available to the public under an Attribution-Noncommercial-Share Alike 3.0 Unported Creative Commons License (http://creativecommons.org/licenses/ by-nc-sa/3.0).

"ASCB ${ }^{\oplus "}$ and "The American Society for Cell Biology ${ }^{\circledR "}$ are registered trademarks of The American Society for Cell Biology. 


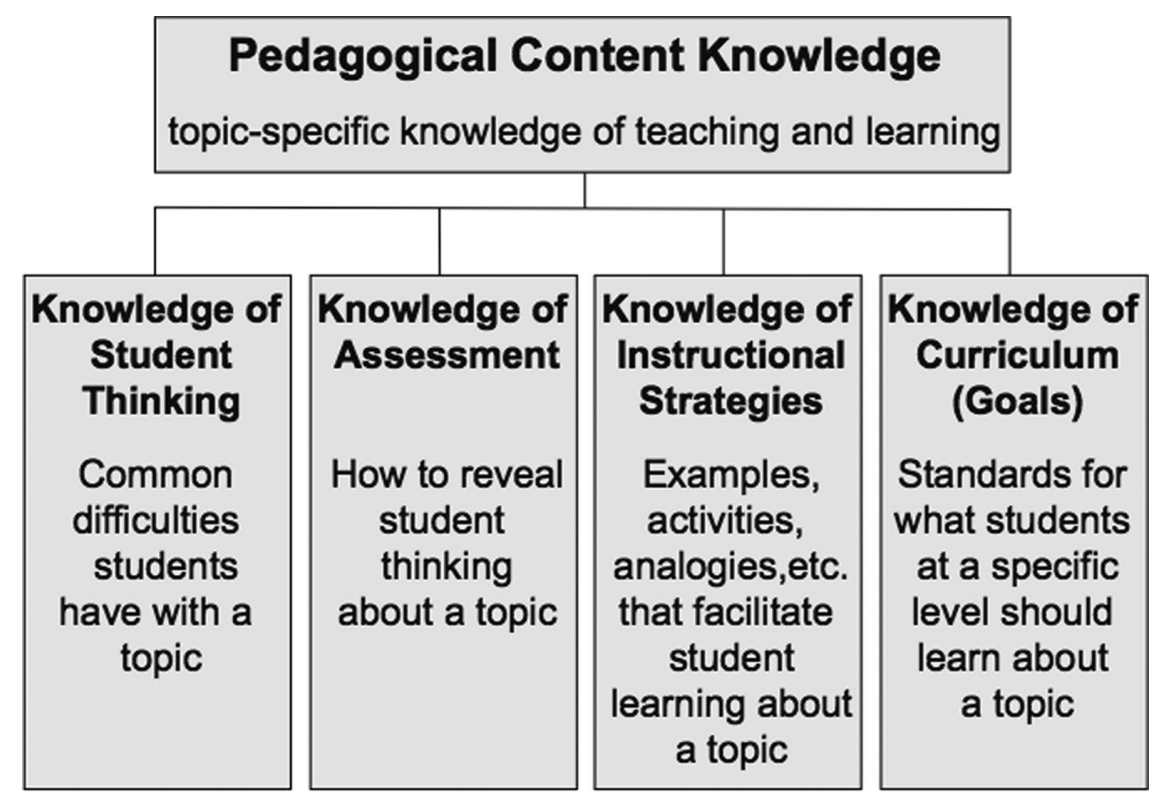

FIGURE 1. Components of PCK addressed in this study.

changes in populations result from adaptive or nonadaptive processes. In addition to knowing this, an undergraduate evolution instructor benefits from knowing that students commonly think all evolutionary change results from natural selection, being able to identify when students express this idea, and having strategies to help students develop more accurate conceptions. The education research community lacks consensus on what components make up PCK, but widely cited work includes these four components (Figure 1): knowledge of student thinking, knowledge of assessment, knowledge of instructional strategies, and knowledge of curriculum (e.g., Shulman, 1987; Magnusson et al., 1999; Park and Oliver, 2008).

Knowledge of student thinking includes awareness of difficulties students are likely to have in thinking about a specific topic, how they will express their thinking, and how their ideas are likely to change as a result of instruction (Schneider, 2015). This component of PCK encompasses what makes topics easy or difficult. For example, undergraduates learning about natural selection often think that new traits arise in a population because individuals need them to survive and that new traits are always beneficial (Gregory, 2009). Anticipating this misconception allows an instructor to plan questions to reveal this thinking and instruction that helps students construct scientifically accurate ideas about natural selection.

Knowledge of assessment includes knowledge of the dimensions of a topic that are important to assess, methods to assess student knowledge of a topic, and how to interpret results of assessment (Park and Oliver, 2008). Continuing with the example of natural selection, there are multiple research-based approaches to assessing undergraduates' thinking about key concepts in natural selection. Forced-response instruments include the Conceptual Inventory of Natural Selection (Anderson et al., 2002) and the Conceptual Assessment of Natural Selection (Kalinowski et al., 2016). Alternatively, instructors can ask constructed-response items from an assessment collection called Assessing Contextual Reasoning about Natural Selection and use an online portal to automatically analyze students' written responses (Moharreri et al., 2014). These instruments are carefully designed to reveal both misconceptions and scientifically accurate ideas. Instructors can use them to gauge students' prior knowledge, measure what students know following instruction, and assess learning gains resulting from instruction.

Knowledge of instructional strategies includes knowledge of topic-specific approaches that help students re-evaluate problematic ideas and construct scientifically accurate ideas, including examples, models, illustrations, analogies, problems, demonstrations, and simulations. For example, a series of simulations in which undergraduates design experiments and collect data about snail shell thickness and predation corrected misconceptions about natural selection among beginning and advanced undergraduates (Abraham et al., 2009). An inquiry-based curriculum based on the digital evolution platform Avida-ED (https://avida-ed.msu .edu) has been shown to increase the level of complexity of undergraduates' explanations about the relationship between mutation and selection (Bray-Speth et al., 2009). An instructor with awareness of these instructional strategies can employ them to facilitate development of students' ideas about natural selection.

Knowledge of curriculum includes knowledge of goals and standards for students learning a topic and knowledge of specific curriculum for teaching a topic at a particular level (Magnusson et al., 1999). This component must be tailored to be relevant to undergraduate education, because state and national standards do not exist for undergraduate education, and college instructors rarely adopt a full curriculum developed by someone else. Nonetheless, instructors benefit from knowledge of learning goals for particular topics. Therefore, knowledge of curriculum at the undergraduate level is best thought of as knowledge of learning goals. One example of work that generates knowledge of learning goals is the BioCore Guide (Brownell et al., 2014). The BioCore Guide is a framework of specific concepts a graduating general biology major should know. Building on Vision and Change (AAAS, 2011), researchers gathered input from more than 240 biologists to arrive at general principles and specific statements about what students should learn about evolution and four other core concepts in biology. These provide guidance to instructors as they develop objectives for what they aim to help their students achieve. Articulating learning objectives is the first step for instructional design (Wiggins and McTighe, 1998).

Instructors need PCK for every topic in evolution they teach, which is a tremendous body of knowledge to develop alone. However, empirical investigations of undergraduates' thinking and learning have produced knowledge that is available in peer-reviewed literature. PCK generated by researchers and practitioners and made accessible for study and use by instructors is 
referred to as "collective" PCK. ${ }^{1}$ Currently, it is unclear whether the collective PCK available adequately addresses the topics undergraduates need to learn. Some propose that education research has focused on natural selection at the expense of other important evolutionary concepts (Padian, 2010; Novick et al., 2014). The BioCore Guide identifies mutation, gene flow, genetic drift, speciation, common ancestry, phylogenetics, evolutionary trade-offs, and sources of phenotypic variation as additional evolutionary topics important for undergraduates to master (Brownell et al., 2014).

The goals of this study were to determine what collective PCK for undergraduate evolution instruction is available and what is missing, to produce a searchable database of available collective knowledge, and to demonstrate that PCK is a useful framework to guide future research on teaching and learning in undergraduate biology education. Specifically, we addressed two research questions:

1. What collective PCK for undergraduate evolution education is available in peer-reviewed literature?

2. How do the topics covered by undergraduate evolution instructors compare with the topics for which collective PCK is currently available?

\section{METHODS}

\section{Identifying Peer-Reviewed Literature}

We aimed to identify all peer-reviewed literature potentially relevant to undergraduate evolution education. We started by searching the Education Resources Information Center (ERIC) database, because this database focuses on education research and information. We conducted a single Boolean search with 26 terms representing topics in evolution (e.g., natural selection, speciation), 19 terms about teaching and learning (e.g., student thinking, instruction), and 14 terms referring to the study population (e.g., undergraduate, postsecondary) (Supplemental Table S1). We used the operators "OR" and "AND" so that each search result contained at least one term from each category.

The ERIC database indexes education journals, and we anticipated that relevant literature had also been published in other journals. Therefore, we also searched within specific journals. We reviewed every published volume of Evolution: Education and Outreach because we expected many articles in this journal to be relevant. We also searched Science, Evolution, Genetics, PLOS, and BioScience. We used more general terms for these journals, including "evolution" and "education." Some of these journals organize papers related to education into searchable collections. In those cases, we reviewed every paper within a collection. We conducted all searches between July and October 2016 and added a few papers published later in 2016.

\section{Screening Peer-Reviewed Literature for Inclusion}

The authors and undergraduate researchers reviewed every article produced by these searches by reading titles, then abstracts, and then full papers as necessary to screen for inclusion in fur-

\footnotetext{
${ }^{1} \mathrm{~A}$ recently proposed "consensus" model of PCK refers to this as "topic-specific professional knowledge" (Gess-Newsome, 2015), but this name has not yet been widely adopted. We, like other researchers, find "collective PCK" to be a more intuitive name (Smith et al., 2016).
}

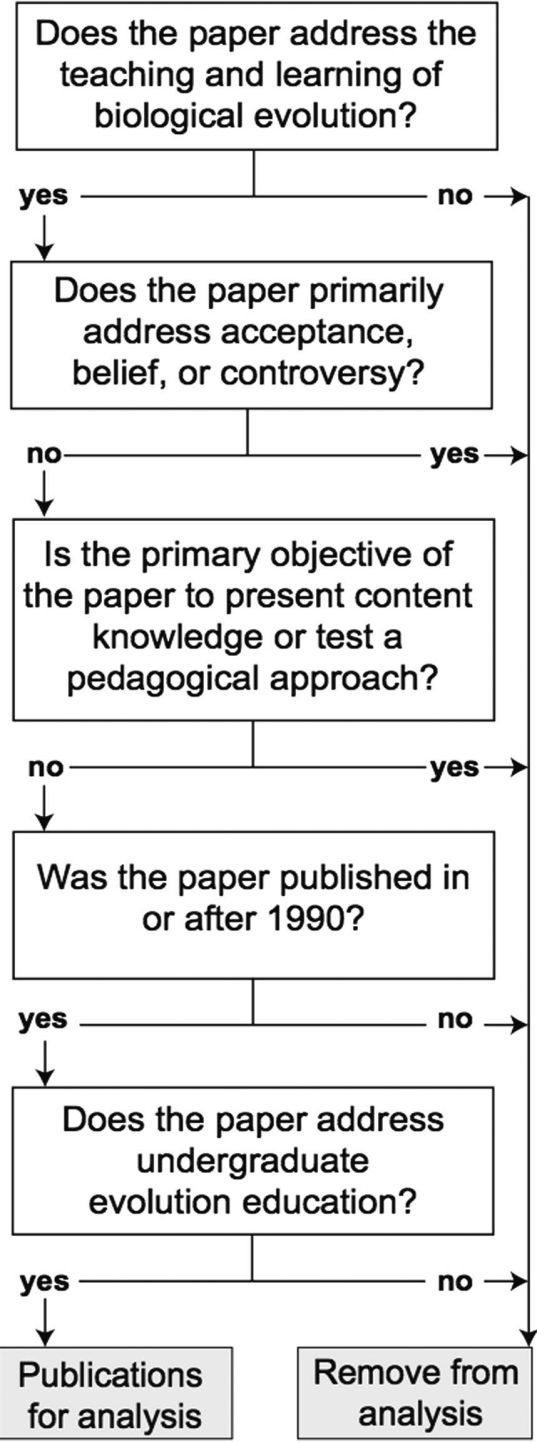

FIGURE 2. Decision tree for screening papers for inclusion in systematic analysis of collective PCK.

ther analysis of collective PCK (Figure 2). If there was any question about the relevance of a publication, we included it for further analysis. We excluded papers that clearly did not address the teaching or learning of biological evolution, such as those that discussed the "evolution" of a history curriculum and papers about legal proceedings, court litigation, and evolution education policy. We also excluded papers that primarily focused on students' beliefs, acceptance, and attitudes regarding evolution. We recognize these papers can be highly valuable to instructors and that affective factors may impact learning, but our aims focused exclusively on cognitive components of evolution education. We did not include papers whose primary objective was to examine a pedagogical approach (e.g., case study teaching, argumentation), rather than to learn about teaching and learning evolution. For example, one study investigated the impact of a fully flipped versus partially flipped classroom on student performance, withdrawal rates, and attitudes toward 
active learning. This study took place in a course about evolution, but teaching and learning evolution were not the focus of the research questions (Adams et al., 2016). Additionally, we excluded papers that primarily presented content knowledge about a topic in evolution. These papers clearly aimed to contribute to instructor knowledge of a particular topic but did not provide insights into PCK. Finally, we also excluded papers published before 1990 and those that described computer resources that were no longer discoverable using an Internet search, because we determined the utility of these papers to instructors to be minimal (Figure 2).

Originally, we intended to include papers about evolution education at the high school level. We expected these papers to be useful in at least two ways. First, papers presenting instructional strategies for high school students could provide ideas for instructors, especially instructors of introductory and smaller college courses. Second, we anticipated that papers investigating student thinking could be useful because advanced high school students and those early in their college career may not differ substantially. We collected and analyzed these papers in the same way that we analyzed papers about undergraduate evolution education. However, we determined that papers about high school evolution education primarily addressed topics and components of PCK that were already well represented by work on undergraduates and did not fill gaps in topic collective PCK. Therefore, we did not include these in our final analysis and results. Some of these papers may provide new ideas for college instructors, so we have included them in our searchable database (see Creating a Searchable Database of Collective Knowledge).

We next evaluated the efficacy of our literature search. We searched reference sections of papers in our collection for relevant work we had not yet identified. Our first round of searching references involved selecting 17 papers we expected to be most likely to cite papers we had not yet identified. We included literature reviews and other papers that extensively reviewed prior work $(n=9)$. We also included papers on evolution topics underrepresented in our sample $(n=8)$, such as evolutionary developmental biology and biodiversity. We examined all peer-reviewed literature cited by these papers and determined which were relevant to our study. If a paper was cited by more than one of these 17 papers, we only counted it once. We found 138 citations relevant to our study. We had already identified $83.3 \%(n=115)$ of these papers. This provided a conservative estimate of the proportion of all relevant literature that we had successfully identified. We added 23 new papers to our collection using this approach.
We repeated this process with a randomly selected sample of 50 papers from our collection to calculate a more general estimate of our search efficacy. We reviewed the citations as described above, and identified 154 papers relevant to our study. We again determined which papers were already part of our collection. We had already identified $96.7 \%(n=149)$ of these papers. We added five new papers to our collection and concluded that our literature search had revealed the vast majority of relevant publications. The final collection included 316 papers relevant to undergraduate evolution education. These publications span 41 peer-reviewed journals, including 29 education journals and 13 discipline-specific journals. Most of these publications focus on U.S. student populations; however, we also found work that studied students in South America, Europe, Australia, and Asia.

\section{Systematic Analysis of the Literature}

We analyzed each of these 316 papers to characterize the collective PCK available by PCK component, type of work, and evolutionary topic.

Identifying PCK Component. The authors independently read abstracts and full papers as necessary to determine what component(s) of PCK each paper addressed, and then discussed any disagreements until we reached consensus. Most papers addressed a single PCK component (student thinking, assessment, instructional strategies, or goals), but some addressed two. Most commonly, papers that addressed two components focused on student thinking and either assessment or instructional strategies. As part of this analysis, we also analyzed the type of work for each paper. We categorized each paper as descriptive, empirical, literature review, or author's perspective (Table 1).

Identifying Evolution Topic. We determined the evolution topic(s) addressed in each paper. We began this process by creating a list of evolutionary topics, drawing on evolution textbooks and our own disciplinary expertise. The authors and undergraduate research assistants independently read each abstract, and papers as necessary, to determine the topic(s) addressed. We gathered as a research team to discuss disagreements until we reached consensus. We iteratively refined this list of topics throughout the analysis process. As the list of evolution topics changed, we re-analyzed papers we had previously considered. After every abstract had been categorized for topic and the list of evolution topics was no longer changing, we examined all

TABLE 1. Descriptions of types of papers, and percent representation by PCK component

\begin{tabular}{|c|c|c|c|c|c|}
\hline Type of paper & Definition & $\begin{array}{l}\text { Percent of } \\
\text { all papers } \\
(n=316)\end{array}$ & $\begin{array}{c}\text { Percent of } \\
\text { student } \\
\text { thinking } \\
(n=64)\end{array}$ & $\begin{array}{l}\text { Percent of } \\
\text { assessment } \\
(n=24)\end{array}$ & $\begin{array}{c}\text { Percent of } \\
\text { instructional } \\
\text { strategies } \\
(n=239)\end{array}$ \\
\hline Descriptive & $\begin{array}{l}\text { Describes an activity, lesson, unit, or course; may provide } \\
\text { resources and student self-report data }\end{array}$ & 51 & 0 & 0 & 67 \\
\hline Empirical & $\begin{array}{l}\text { Presents data collected and systematically analyzed to } \\
\text { answer a research question }\end{array}$ & 37 & 83 & 92 & 23 \\
\hline Author's perspective & $\begin{array}{l}\text { Presents an argument, drawing on existing literature and } \\
\text { professional experience }\end{array}$ & 10 & 8 & 8 & 9 \\
\hline Literature review & Extensively reviews existing empirical literature & 2 & 9 & 0 & 1 \\
\hline
\end{tabular}


papers within a single topic. We examined related topics at the same time to clarify the boundaries between topics. This approach helped us to refine the descriptions of each topic.

Some topics in our final list are organized into overarching categories. This structure was necessary to make comparisons between peer-reviewed literature and topics covered in evolution courses. We grouped large-scale patterns in evolution, major transitions in the history of life, and deep time into the overarching category of macroevolution. We also organized tree-thinking and systematics together under phylogenetics. Finally, we organized population genetic modeling, allelic interactions, Hardy-Weinberg equilibrium, and genetic drift within the overarching category of population genetics.

Creating a Searchable Database of Collective Knowledge. We organized the data produced by these analyses into an Excel file to create a searchable database. The database includes the 316 relevant papers and is organized by PCK component, type of work, evolution topic, journal, and publication year. The database also includes a worksheet with 93 papers about high school evolution education organized in the same way (see the Supplemental Material).

\section{Identifying and Comparing Topics Taught in Undergraduate Evolution Courses}

We aimed to compare the collective PCK accessible in the peer-reviewed literature with what is relevant to undergraduate evolution instructors. We used course syllabi from evolution courses as a proxy for what evolution instructors see as important topics in undergraduate evolution education. We limited our search to courses that taught evolution broadly, excluding courses with more specific foci (e.g., macroevolution, evolution of flowering plants, molecular evolution) and broader foci (e.g., introductory biology, cell biology, zoology). We focused on upper-division evolution courses because we expected them to cover a greater diversity of topics in evolution than lower-division courses. We collected syllabi from around the country, focusing on large, public universities. We searched university websites for publicly available syllabi, but found few. Therefore, we used course schedules and class bulletins to identify the course number for upper-division evolution courses and instructors who had recently taught the course. We emailed instructors directly to ask if they would be willing to share their most recent syllabi. We collected syllabi from 32 upper-level evolution courses spanning 25 states and 27 institutions. We analyzed each syllabus to determine the topics taught in each course. In the analysis presented here, we focused on topics taught in at least $40 \%$ of the courses we surveyed. We compared these topics with what we found in our collection of peer-reviewed papers. We made comparisons between overarching topic categories for macroevolution, phylogenetics, and population genetics, because syllabi often did not describe these topics at a finer grain size.

\section{RESULTS \\ Analysis of Peer-Reviewed Literature by PCK Component and Type of Work}

Out of 316 papers about undergraduate evolution education, $75 \%$ presented instructional strategies $(n=239), 21 \%$ addressed student thinking $(n=64)$, and $8 \%$ dealt with assessment $(n=$ 24). Six papers (2\%) concentrated on goals for undergraduate evolution instruction. Fifteen papers addressed more than one component of PCK.

Student Thinking. These papers investigated or summarized student thinking about specific topics in evolution. Most of these studies were empirical (Table 1). For example, one paper examined the effects of college students' prior knowledge on their ability to reason from information depicted in cladograms and found that students demonstrated more sophisticated reasoning when the taxa were unfamiliar and they had to rely solely on the diagrammatic information presented rather than prior knowledge (Novick and Catley, 2014). Other papers reviewed empirical work, providing a distilled resource for instructors. For example, one paper described the process of natural selection, discussed possible causes of misconceptions, and reviewed the most common misconceptions undergraduates possess about natural selection and adaptive evolution (Gregory, 2009). Finally, some papers presented authors' professional perspectives about the origins and causes of difficulties students have in learning topics in evolution.

Assessment. Papers about assessment described the development and validation of instruments to measure student understanding about a topic in evolution, further evaluated previously published instruments, and addressed theoretical questions about assessment. Most assessment papers were empirical (Table 1). For example, one paper described the EvoDevoCI, which measures student thinking about six core concepts in evolutionary developmental biology (Perez et al., 2013). Other researchers conducted a distracter analysis of the Conceptual Inventory of Natural Selection using item response theory and suggested test items that require revision (Battisti et al., 2010).

Instructional Strategies. These papers addressed strategies for teaching topics in evolution. Some papers described specific strategies, ranging in grain size from a single activity or class period to a full course. For example, one paper described and evaluated a laboratory exercise in which students develop and test simple hypotheses about sperm competition in humans (Cotner and Gallup, 2011). Another paper described and evaluated an entire evolutionary biology course that uses emerging infectious diseases as a case study to appeal to students who aspire to become health professionals at a historically Black college (Pai, 2009). Papers discussing instructional strategies described strategies, with or without collecting empirical data to assess efficacy (Table 1). Some presented author perspectives on broader issues. For example, one essay argued that origin of life and prebiotic evolution should be part of the undergraduate biology curriculum (Lazcano and Peretó, 2010).

Goals. We identified six papers that dealt with goals for undergraduate evolution education. In addition to the BioCore Guide, which outlines learning goals for multiple topics in evolution, we found five papers that outlined goals for specific topics. For example, one paper outlined four central points that students need to understand about coevolution (Thompson, 2010), and another identified core concepts for teaching developmental aspects of evolution (Hiatt et al., 2013). Two papers about goals were empirical (Hiatt et al., 2013; Brownell et al., 2014), and 
TABLE 2. Descriptions of evolution topics, some of which are grouped in overarching categories (indented)

\begin{tabular}{|c|c|}
\hline Topic & Description of how topic was operationalized in papers \\
\hline Natural selection & Natural selection, heritable variation, differential fitness/reproductive success, adaptation \\
\hline \multicolumn{2}{|l|}{ Macroevolution } \\
\hline Macro patterns & Phyletic gradualism and punctuated equilibrium, biogeography \\
\hline Major transitions & Origin of life, origin of the cells, evolution of multicellularity, extinction \\
\hline Deep time & Time frame of the history of earth, including geological and paleontological evidence \\
\hline Speciation & Species concepts, fossil evidence of speciation \\
\hline Systematics & Building trees with morphological and molecular data; homology and homoplasy \\
\hline \multicolumn{2}{|l|}{ Population genetics } \\
\hline Pop gen modeling & Mathematical models of population genetics, effective population size \\
\hline Allelic interactions & Dominance in allelic pairs, heterozygosity, heterozygote advantage \\
\hline Genetic drift & Random sampling of alleles that results in changes in allele frequencies \\
\hline Molecular evolution & Rate of mutation, chromatin evolution, protein evolution, molecular clock \\
\hline Sexual selection & Mate choice, male-male competition, sexual behavior, sexual and natural selection tension \\
\hline Coevolution & Predator-prey and plant-herbivore interactions, coevolutionary arms race, Red Queen \\
\hline Quantitative genetics & Variation in quantitative traits \\
\hline Evolutionary medicine & Application of evolution to the study of human health \\
\hline Biodiversity & Intraspecies diversity, biogeography \\
\hline EvoDevo & Evolutionary developmental biology, heterochrony, heterotopy, organogenesis \\
\hline Human impact & Human impacts on contemporary evolution \\
\hline Evolution broadly & Papers in this category did not focus on any particular topic in evolution. \\
\hline
\end{tabular}

four presented the authors' perspectives (Brewer, 1996; Baum and Offner, 2008; Thompson, 2010; Gregory et al., 2011).

\section{Analysis of Peer-Reviewed Literature by Evolutionary Topic}

We identified 22 distinct evolutionary topics, and most papers (78\%) addressed one or more of these (Table 2 ). The other $22 \%$ of papers addressed evolution broadly without specifying topic more narrowly. Natural selection, phylogenetics, and evolution broadly accounted for $69 \%$ of published papers. Eight topics were addressed by five or fewer papers (Table 3). One hundred and seven papers addressed more than one topic. The majority of this overlap occurred within overarching categories (macroevolution, phylogenetics, and population genetics).

We also examined topic representation by PCK component to more richly characterize gaps in available collective PCK (Table 3). The representation of evolutionary topics across papers addressing instructional strategies was reflective of our complete collection of papers, but this was not true for papers focusing on student thinking or assessment. Student thinking papers largely focused on tree thinking, natural selection, and evolution broadly. Ten topics in evolution were not addressed by a single student-thinking paper (Table 3). Assessment papers focused primarily on natural selection and tree thinking, and 14 topics were not addressed by a single assessment paper. Papers about goals for undergraduate evolution education addressed coevolution $(n=1)$, evolutionary developmental biology $(n=$ $1)$, phylogenetics $(n=2)$, and evolution broadly $(n=2)$.

\section{Comparison between Topics Covered by Evolution Instructors and Available Collective PCK}

We identified 17 topics that were covered in at least $40 \%$ of the 32 upper-division evolution courses we sampled from around the country. These topics were not equally represented in the peer-reviewed literature on undergraduate evolution education (Figure 3). Nearly all courses covered natural selection, macroevolution, speciation, phylogenetics, and population genetics, but the number of papers addressing these topics varied considerably (Figure 3). More than 140 papers addressed natural selection or phylogenetics, but only 50 papers addressed macroevolution, speciation, or population genetics (Figure 3). Eighty-one papers addressed the remaining 12 topics, and two topics covered in almost $60 \%$ of courses were not addressed by any peer-reviewed paper (Figure 3).

\section{DISCUSSION}

One aim of this paper was to demonstrate the utility of pedagogical content knowledge as a framework for analyzing existing research and providing a road map for future work. We have addressed this aim by identifying gaps in the collective PCK currently available for undergraduate evolution education, and now propose priorities for the research community. We first outline priorities by evolution topic. Next, we propose that research on student thinking is fundamental and therefore should be prioritized. Finally, we consider the value of different types of work, including literature reviews, empirical investigations, and 
TABLE 3. Number of papers $(n=316)$ by PCK component and evolution topic

\begin{tabular}{|c|c|c|c|}
\hline Topic & $\begin{array}{l}\text { Student } \\
\text { thinking } \\
(n=64)^{\mathrm{a}}\end{array}$ & $\begin{array}{c}\text { Assessment } \\
(n=24)^{\mathrm{a}}\end{array}$ & $\begin{array}{c}\text { Instructional } \\
\text { strategy } \\
(n=239)^{\mathrm{a}}\end{array}$ \\
\hline Natural selection & 16 & 10 & 69 \\
\hline \multicolumn{4}{|l|}{ Macroevolution } \\
\hline Macro patterns & 1 & 0 & 3 \\
\hline Major transitions & 1 & 0 & 5 \\
\hline Deep time & 2 & 2 & 3 \\
\hline Speciation & 0 & 2 & 8 \\
\hline \multicolumn{4}{|l|}{ Phylogenetics } \\
\hline Tree thinking & 18 & 8 & 12 \\
\hline Systematics & 4 & 1 & 27 \\
\hline \multicolumn{4}{|l|}{ Population genetics } \\
\hline $\begin{array}{l}\text { Population genetics } \\
\text { modeling }\end{array}$ & 0 & 0 & 6 \\
\hline Allelic interactions & 0 & 1 & 2 \\
\hline Genetic drift & 3 & 1 & 9 \\
\hline Hardy-Weinberg & 0 & 0 & 5 \\
\hline Origin of variation & 2 & 0 & 10 \\
\hline Evolution of behavior & 1 & 0 & 11 \\
\hline Human evolution & 1 & 0 & 13 \\
\hline Molecular evolution & 0 & 0 & 12 \\
\hline Sexual selection & 0 & 0 & 5 \\
\hline Coevolution & 0 & 0 & 5 \\
\hline Quantitative genetics & 0 & 0 & 1 \\
\hline Evolutionary medicine & 0 & 0 & 5 \\
\hline Biodiversity & 1 & 0 & 5 \\
\hline EvoDevo & 1 & 1 & 7 \\
\hline Human impact & 0 & 0 & 2 \\
\hline Evolution broadly & 21 & 1 & 48 \\
\hline
\end{tabular}

Key: Shading indicates number of papers.

\begin{tabular}{l|l|l|l|l}
$0-4$ & $5-9$ & $10-14$ & $15-19$ & $20+$
\end{tabular}

${ }^{\mathrm{a}} \mathrm{A}$ total of 106 papers were coded for multiple topics: 80 were coded for two topics, 21 were coded for three topics, 1 was coded for four topics, 2 were coded for five topics, and 2 were coded for six topics.

descriptions of instructional strategies, and propose priorities for types of work going forward.

\section{Evolution Topics That Are Top Priority for Future Research} As anticipated, natural selection has received much more attention than other evolution topics. This is despite the breadth of topics taught in undergraduate evolution courses (Figure 3) and evidence that learning natural selection does not prepare students to do well on other topics in evolution (e.g., Padian, 2010; Novick et al., 2014; Price and Perez, 2016). Though natural selection is a central mechanism in evolution, it is insufficient to focus primarily on adaptive evolution in an undergraduate evolution course. Focusing primarily on natural selection runs the risk of exacerbating an existing problem: undergraduates often mistakenly conflate evolution and natural selection (e.g., Jakobi, 2010; Beggrow and Nehm, 2012). Furthermore, undergraduates' understanding of natural selection may improve as a result of effective instruction for other evolutionary topics (Price and Perez, 2016).

We propose that four evolutionary topics warrant immediate attention from the research community: macroevolution, spe- ciation, quantitative genetics, and population genetics. We generated this list by considering: topics that were taught in at least $60 \%$ of the courses we surveyed, topics for which collective PCK is largely unavailable (Figure 3), and topics that have been identified as core ideas in biology by the community (e.g., Padian, 2010; AAAS, 2011; Brownell et al., 2014; Cary and Branchaw, 2017). It is important to note that there are many finer-grain concepts encompassed by each of these topics. Our analysis did not reveal many papers about learning goals, but a critical first step for the research and education community will be identifying a list of learning goals undergraduates should achieve for these topics. Once the community has generated a list of key concepts, researchers can investigate student thinking about each concept within a topic, develop and refine assessments, and begin testing instructional approaches. Another potentially promising approach to discovering PCK for these critical topics is interviewing experienced and effective undergraduate evolution instructors to discover what they know about teaching and learning these topics. Instructors generate their own PCK through careful reflection on their own instruction (Gess-Newsome, 2015) and are likely to be a rich source of knowledge that can be useful to other instructors.

There are other topics that are commonly taught in college evolution courses and for which limited collective PCK is available. The evolution of behavior, molecular evolution, sexual selection, and coevolution were each taught in more than $60 \%$ of the courses we surveyed but have been the focus of little or no research on student thinking and assessment. These are not explicitly included in lists of core ideas for biology (e.g., Brownell et al., 2014; Cary and Branchaw, 2017); however, they are clearly important for upper-division evolution courses, which are required for many undergraduate life sciences majors. Therefore, we encourage the evolution education research community to consider these four topics as being in need of attention as well.

\section{Research on Student Thinking Is Foundational to Both Teaching and Education Research}

We propose that research on student thinking take priority over other PCK components, because it is foundational to both teaching and education research. First, the development of research-based assessments and instructional strategies depends on knowing both the difficulties students are likely to have in learning a topic and how their thinking can change throughout instruction. Thus, researchers need empirical data on student thinking to develop assessment and instructional strategies. Research on student thinking and research on ways to reveal their thinking (i.e., assessment) can often be conducted in tandem, meaning that progress in generating collective PCK about student thinking can occur simultaneously with progress in generating collective PCK about assessment. Second, even if extensive collective PCK for assessment and instructional strategies were available, college biology instructors would still create formative and summative assessments and lessons of their own design. Therefore, college instructors also stand to benefit disproportionately from research on student thinking compared with research on assessment and instructional strategies. Additionally, knowledge of student thinking is crucial for effective teaching, and this is especially true for student-centered instruction. For example, college 


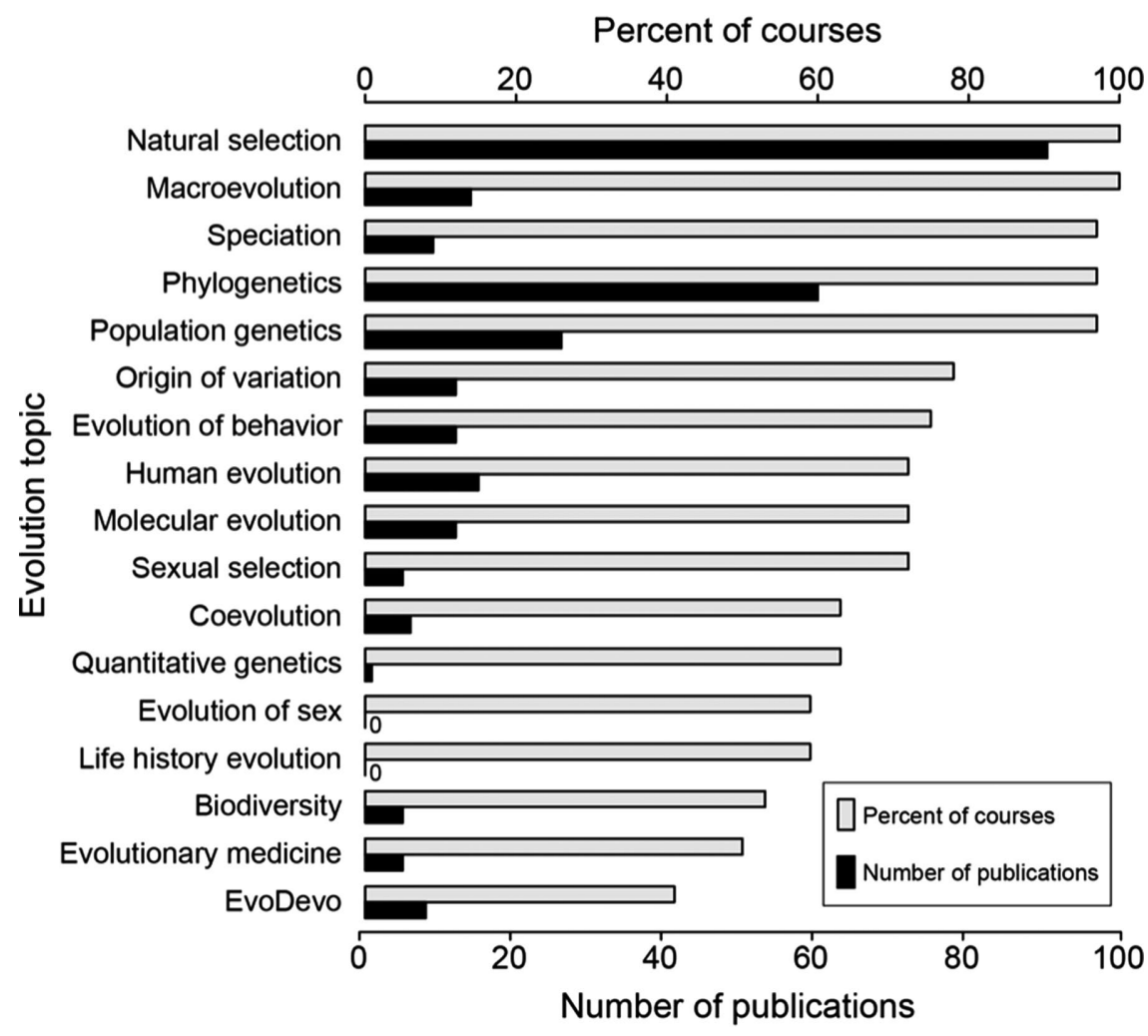

FIGURE 3. Topics taught in upper-division evolution courses compared with topic representation in the peer-reviewed literature. Topics were included if they were listed in more than $40 \%$ of course syllabi $(n=32)$.

math instructors learning to use an inquiry-based curriculum struggled because they could not anticipate the difficulties students were likely to have and were unable to make sense of student reasoning during class discussions (Wagner et al., 2007; Speer and Wagner, 2009; Johnson and Larsen, 2012). These instructors were constrained by their lack knowledge of student thinking.

\section{Literature Reviews Are Scarce, but Most Likely to Be High Impact}

We propose that the research community also continue to produce literature reviews about student thinking and assessment for topics in evolution. We suspect that literature reviews are most useful to instructors because they distill collective PCK from multiple empirical investigations, considerably minimizing the number of papers an instructor needs to read. For example, one literature review summarized common misconceptions about phylogenetics, the relationships among these misconceptions, and their cognitive origins (Meisel, 2010). An instructor can access knowledge generated by more than 20 empirical investigations of student thinking about phylogenetics by reading this single paper. Currently, there are only a few topics with a sufficient body of research on student thinking to warrant a literature review, and Evolution: Education and Outreach has led the way by publishing literature reviews written with instructors in mind (e.g., Gregory, 2008, 2009; Meisel, 2010). We found no reviews for assessment, but college instructors would likely benefit from a paper that reviewed all published, research- based assessments for topics in evolution. Instructors need to know the key concepts and misconceptions addressed in each assessment, the target population, and considerations related to validity and reliability in order to select assessment appropriate for their students and instructional goals. We encourage the community to continue to write reviews with college instructors in mind as more empirical work accumulates regarding student thinking and approaches to revealing student thinking.

\section{Papers about Instructional Strate- gies Should Identify and Empirically Test Which Components Are Critical to Student Learning}

Papers about instructional strategies may provide ideas and inspiration to instructors, but most do not contribute to an overall body knowledge about how to facilitate learning about topics in evolution. We identify two areas for improvement for future papers presenting instructional strategies. First, existing papers often do not carefully consider the components of a strategy that are essential for student learning. We propose that a fidelity of implementation framework is a fruitful approach for considering critical components of an instructional strategy (e.g., Stains and Vickrey, 2017). Critical components of an instructional strategy include 1) the procedures of how a strategy is intended to be implemented; 2) what knowledge instructors must possess to effectively implement the strategy; 3 ) how the instructor should behave and interact with students while implementing the strategy; and 4) how students should interact with the instructor, peers, and learning materials during implementation (Stains and Vickrey, 2017). Identifying what components make a strategy effective is important for the developer and other instructors who may use the strategy, regardless of whether the strategy has been empirically tested. Considering critical components encourages the developer to be more reflective about the instructional strategy and how it influences student outcomes, which is a valuable exercise for developing personal teaching expertise (e.g., McAlpine et al., 1999). Even more importantly, other instructors are more likely to be successful in implementing a published instructional strategy if the developer has clearly articulated his or her thinking about what is essential for student learning.

Second, instructional strategies that have been empirically demonstrated to be effective at facilitating student learning in one instructional context generally require further study to make them generalizable to other instructional contexts. Ultimately, the critical components of an instructional strategy must be determined empirically. As an example, Kalinowski et al. (2013) demonstrated that six classroom exercises for teaching natural selection can be highly effective at facilitating student learning in one instructional context. They addressed the four critical components in their paper and proposed hypotheses 
about what made these classroom exercises effective. These are important first steps, but additional empirical work is necessary to test their hypotheses. Without this follow-up, we fail to move the field toward generalizable principles for instructional strategies for teaching natural selection to undergraduates. Wide adoption of the fidelity of implementation framework by the education research community will allow us to begin making comparisons across instructional strategies. Only then will we have generated collective PCK for instructional strategies that is generalizable beyond single classrooms.

\section{Limitations}

We encourage readers to consider three limitations of this work. First, the reality of any analysis of prior literature is that it is immediately out of date, because new work is always being published. We hope that this paper lays the groundwork for continuing to monitor the progress of evolution education research. Second, there are likely some articles we did not identify. This is most problematic if the missing papers contribute to filling the gaps we identified. We conducted a reference check with this in mind, but we recognize that there are limitations to that approach for testing our efficacy as well. Third, most of the work we were able to find focuses on undergraduates in the United States and therefore may not be generalizable to other student populations.

\section{CONCLUSIONS}

Our work is the first to demonstrate the utility of PCK as a lens for analyzing existing work relevant to undergraduate biology education. We found that collective PCK available in peer-reviewed literature does not adequately address the topics in evolution that college instructors teach. Many topics for which little or no collective PCK is available are taught in the majority of upper-division evolution courses. Given the importance of teacher knowledge to effective instruction and the centrality of student thinking to evidence-based instructional practices, identifying and filling the gaps in our collective knowledge is critical to maximizing the utility of education research to college instruction.

\section{ACKNOWLEDGMENTS}

We thank Raheela Charania, Dustin Dial, and Nnaji Emetu for their research assistance on this project. We also thank the University of Georgia (Athens, GA) Biology Education Research Group for constructive feedback and support throughout this work. We thank three anonymous reviewers and the monitoring editor for helpful feedback that improved the quality of this work. Partial funding was provided by a National Science Foundation Graduate Research Fellowship awarded to M.A.Z. (grant no. DGE-1443117). Any opinions, findings, and conclusions or recommendations expressed in this material are those of the authors and do not necessarily reflect the views of the National Science Foundation.

\section{REFERENCES}

Abraham, J. K., Meir, E., Perry, J., Herron, J. C., Maruca, S., \& Stal, D. (2009) Addressing undergraduate student misconceptions about natural selection with an interactive simulated laboratory. Evolution: Education and Outreach, 2(3), 393-404

Adams, A. E., Garcia, J., \& Traustadóttir, T. (2016). A quasi experiment to determine the effectiveness of a "partially flipped" versus "fully flipped" undergraduate class in genetics and evolution. CBE-Life Sciences Education, 15(2), ar11.
American Association for the Advancement of Science. (2011). Vision and change: A call to action (Final report). Washington, DC.

Anderson, D. L., Fisher, K. M., \& Norman, G. J. (2002). Development and evaluation of the Conceptual Inventory of Natural Selection. Journal of Research in Science Teaching, 39, 952-978. doi: 10.1002/tea.10053

Andrews, T. M., Leonard, M. J., Colgrove, C. A., \& Kalinowski, S. T. (2011). Active learning not associated with student learning in a random sample of college biology courses. CBE-Life Sciences Education, 10(4), 394-405.

Ball, D. L., Thames, M. H., \& Phelps, G. (2008). Content knowledge for teaching: What makes it special? Journal of Teacher Education, 59(5), 389-407.

Battisti, B. T., Hanegan, N., Sudweeks, R., \& Cates, R. (2010). Using item response theory to conduct a distracter analysis on Conceptual Inventory of Natural Selection. International Journal of Science and Mathematics Education, 8(5), 845-868.

Baum, D. A., \& Offner, S. (2008). Phylogenics \& tree-thinking. American Biology Teacher, 70(4), 222-229.

Beggrow, E. P., \& Nehm, R. H. (2012). Students' mental models of evolutionary causation: Natural selection and genetic drift. Evolution: Education and Outreach, 5(3), 429-444

Bray-Speth, E. B., Long, T. M., Pennock, R. T., \& Ebert-May, D. (2009). Using Avida-ED for teaching and learning about evolution in undergraduate introductory biology courses. Evolution: Education and Outreach, 2(3), 415-428.

Brewer, S. (1996). A problem-solving approach to the teaching of evolution. Bioscene, 22(2), 11.

Brownell, S. E., Freeman, S., Wenderoth, M. P., \& Crowe, A. J. (2014). BioCore Guide: A tool for interpreting the core concepts of Vision and Change for biology majors. CBE-Life Sciences Education, 13(2), 200-211.

Cary, T., \& Branchaw, J. (2017). Conceptual elements: A detailed framework to support and assess student learning of biology core concepts. CBELife Sciences Education, 16(2), ar24.

Coley, J. D., \& Tanner, K. D. (2012). Common origins of diverse misconceptions: Cognitive principles and the development of biology thinking. CBE-Life Sciences Education, 11, 209-215.

Cotner, S., \& Gallup, G. G., Jr. (2011). Introductory biology labs... They just aren't sexy enough! Bioscience Education, 18(1), 1-11.

Garvin-Doxas, K., \& Klymkowsky, M. W. (2008). Understanding randomness and its impact on student learning: Lessons learned from building the Biology Concept Inventory (BCl). CBE-Life Sciences Education, 7(2), 227-233.

Gess-Newsome, J. (2015). A model of teacher professional knowledge and skill including PCK. In Berry, A., Friedrichsen, P., \& Loughran, J. (Eds.), Re-examining pedagogical content knowledge in science education (pp. 28-42). New York: Routledge.

Gregory, E., Ellis, J. P., \& Orenstein, A. N. (2011). A proposal for a common minimal topic set in introductory biology courses for majors. American Biology Teacher, 73(1), 16-21.

Gregory, T. R. (2008). Understanding evolutionary trees. Evolution: Education and Outreach, 1(2), 121

Gregory, T. R. (2009). Understanding natural selection: Essential concepts and common misconceptions. Evolution: Education and Outreach, 2(2), $156-175$.

Hiatt, A., Davis, G. K., Trujillo, C., Terry, M., French, D. P., Price, R. M., \& Perez K. E. (2013). Getting to evo-devo: Concepts and challenges for students learning evolutionary developmental biology. CBE-Life Sciences Education, 12(3), 494-508.

Hill, H. C., Rowan, B., \& Ball, D. L. (2005). Effects of teachers' mathematical knowledge for teaching on student achievement. American Educational Research Journal, 42(2), 371-406.

Jakobi, S. R. (2010). "Little monkeys on the grass..." How people for and against evolution fail to understand the theory of evolution. Evolution: Education and Outreach, 3(3), 416-419.

Johnson, E. M., \& Larsen, S. P. (2012). Teacher listening: The role of knowledge of content and students. Journal of Mathematical Behavior, 31(1), 117-129.

Kalinowski, S. T., Leonard, M. J., Andrews, T. M., \& Litt, A. R. (2013). Six classroom exercises to teach natural selection to undergraduate biology students. CBE-Life Sciences Education, 12(3), 483-493. 
Kalinowski, S. T., Leonard, M. J., \& Taper, M. L. (2016). Development and validation of the Conceptual Assessment of Natural Selection (CANS). CBELife Sciences Education, 15(4), ar64.

Lazcano, A., \& Peretó, J. (2010). Should the teaching of biological evolution include the origin of life? Evolution: Education and Outreach, 3(4) 661-667.

Lecoutre, M.-P., Rovira, K., Lecoutre, B., \& Poitevineau, J. (2006). People's intuition about randomness and probability: An empirical study. Statistics Educational Research Journal, 5, 20-35

Magnussen, S., Krajcik, J., \& Borko, H. (1999). Nature, source, and development of pedagogical content knowledge. In Gess-Newsome, J., \& Lederman, N. G. (Eds.), Examining pedagogical content knowledge (pp. 95-132). Dordrecht, Netherlands: Kluwer.

McAlpine, L., Weston, C., Beauchamp, C., Wiseman, C., \& Beauchamp, J. (1999). Building a metacognitive model of reflection. Higher Education, 37(2), 105-131.

Meisel, R. P. (2010). Teaching tree-thinking to undergraduate biology students. Evolution: Education and Outreach, 3(4), 621-628.

Moharreri, K., Ha, M., \& Nehm, R. H. (2014). EvoGrader: An online formative assessment tool for automatically evaluating written evolutionary explanations. Evolution: Education and Outreach, 7(1), 15

Nehm, R. H., Rector, M. A., \& Ha, M. (2010). "Force-talk" in evolutionary explanation: Metaphors and misconceptions. Evolution: Education and Outreach, 3(4), 605-613.

Nehm, R. H., \& Reilly, L. (2007). Biology majors' knowledge and misconceptions of natural selection. BioScience, 57, 263-272.

Novick, L. R., \& Catley, K. M. (2014). When relationships depicted diagrammatically conflict with prior knowledge: An investigation of students interpretations of evolutionary trees. Science Education, 98(2), 269-304

Novick, L. R., Schreiber, E. G., \& Catley, K. M. (2014). Deconstructing evolution education: The relationship between micro-and macroevolution. Journal of Research in Science Teaching, 51(6), 759-788.

Padian, K. (2010). How to win the evolution war: Teach macroevolution!. Evolution: Education and Outreach, 3(2), 206-214.

Pai, A. (2009). Evolution in Action, a case study based advanced biology class at Spelman College. Journal of Effective Teaching, 9(2), 54-68.

Park, S., \& Oliver, J. S. (2008). Revisiting the conceptualisation of pedagogical content knowledge (PCK): PCK as a conceptual tool to understand teachers as professionals. Research in Science Education, 38(3), 261-284.

Perez, K. E., Hiatt, A., Davis, G. K., Trujillo, C., French, D. P., Terry, M., \& Price, R. M. (2013). The EvoDevoCl: A concept inventory for gauging students understanding of evolutionary developmental biology. CBE-Life Sciences Education, 12(4), 665-675.

Phillips, B. C., Novick, L. R., Catley, K. M., \& Funk, D. J. (2012). Teaching tree thinking to college students: It's not as easy as you think. Evolution: Education and Outreach, 5(4), 595-602.

Price, R. M., Andrews, T. C., McElhinny, T. L., Mead, L. S., Abraham, J. K., Thanukos, A., \& Perez, K. E. (2014). The Genetic Drift Inventory: A tool for measuring what advanced undergraduates have mastered about genetic drift. CBE-Life Sciences Education, 13(1), 65-75.

Price, R. M., \& Perez, K. E. (2016). Beyond the adaptationist legacy: Updating our teaching to include a diversity of evolutionary mechanisms. American Biology Teacher, 78(2), 101-108.

Sadler, P. M., Sonnert, G., Coyle, H. P., Cook-Smith, N., \& Miller, J. L. (2013) The influence of teachers' knowledge on student learning in middle school physical science classrooms. American Educational Research Journal, 50(5), 1020-1049.

Schneider, R. M. (2015). Pedagogical content knowledge reconsidered: A teacher educator's perspective. In Berry, A., Friedrichsen, P., \& Loughran, J. (Eds.), Re-examining pedagogical content knowledge in science education (pp. 162-177). New York: Routledge.

Shulman, L. S. (1987). Knowledge and teaching: Foundations of the new reform. Harvard Educational Review, 57(1), 1-23.

Smith, M. U. (2010). Current status of research in teaching and learning evolution. II. Pedagogical issues. Science \& Education, 19(6-8), 539-571.

Smith, P. S., Esch, R. K., Hayes, M. L., \& Plumley, C. L. (2016). Developing and testing a method for collecting and synthesizing pedagogical content knowledge. Presented at:the NARST Annual International Meeting, Baltimore, MD.

Speer, N. M., \& Wagner, J. F. (2009). Knowledge needed by a teacher to provide analytic scaffolding during undergraduate mathematics classroom discussions. Journal for Research in Mathematics Education, 530-562.

Stains, M., \& Vickrey, T. (2017). Fidelity of implementation: An overlooked yet critical construct to establish effectiveness of evidence-based instructional practices. CBE-Life Sciences Education, 16(1), rm1.

Thompson, J. N. (2010). Four central points about coevolution. Evolution: Education and Outreach, 3(1), 7-13.

Wagner, J. F., Speer, N. M., \& Rossa, B. (2007). Beyond mathematical content knowledge: A mathematician's knowledge needed for teaching an inquiry-oriented differential equations course. Journal of Mathematical Behavior, 26(3), 247-266.

Wiggins, G., \& McTighe, J. (1998). Backward design. In Understanding by design (pp.13-34). Alexandria, VA: ASCD. 